\title{
An Interesting Case of Osmotic Demyelination Syndrome, with two Cerebrovascular Accidents in a Post Liver Transplant Patient
}

\author{
Authors \\ R.Kanimozhi ${ }^{1}$, Karthick Kamal ${ }^{1}$, Satish Logidasan ${ }^{2}$, Arulraj Panchatcharam ${ }^{3}$ \\ Karthik Prakasam $^{4}$, S R Karthick ${ }^{5}$, Gowrishankar Anjaneyan ${ }^{6}$, Prasana Vadhavanan ${ }^{7}$ \\ Ambal S ${ }^{8}$ \\ ${ }_{1,2,3,4,5,6,7,8}$ Department of Anesthesiology, Govt Stanley Medical College, TN- 600001,India \\ ${ }^{1}$ Karthick Kamal, Department of Anesthesiology, Kilpauk Medical College \\ Corresponding Author \\ Satish Logidasan \\ Department of Anesthesiology, Govt Stanley Medical College, TN- 600001, India \\ Email:drsatishlogi@gmail.com
}

\begin{abstract}
Though ODS is perceived to be a dreadful complication classically occurring after aggressive therapy for hyponatremia, it is important to recognise that osmotic demyelination can develop in patients with any levels of sodium, indicating the contribution of other factors ${ }^{[1]}$. Alcohol abuse, liver transplantation, malnutrition ${ }^{[2,}$ 3] are strong independent risk factors for the development of ODS. We present the events in a case of an Ethanol related Decompensated Liver Disease(DCLD), who developed ODS after liver transplantation, with normal sodium levels, who eventually suffered an embolic stroke later and a cerebral hemorrhage towards discharge.
\end{abstract}

Keywords: Osmotic Demyelination Syndrome, Liver transplant, electrolyte and fluid imbalance.

\section{Introduction}

We briefly narrate the postoperative course of a liver transplant patient who had developed ODS (Osmotic Demyelination Syndrome). We had a 42years old, malnourished (BMI 19.5), alcohol induced Decompensated Chronic Liver Disease (DCLD) patient, whose MELD score was 33, in the waiting list with all the preoperative work up done. He had no comorbid illness except for hypothyroidism, was on tablet Eltroxin 100mics. His preoperative MRI had hyperintensity in the bilateral basal ganglia. DDLT was done when a suitable donor was available.

\section{Intra operative events}

The mild hypotension (BP 82/60mmHg) in the anhepatic phase was managed with noradrenaline infusion at a rate of $0.01 \mathrm{mic} / \mathrm{kg} / \mathrm{min}$. BP improved to $112 / 72$ to $120 / 74 \mathrm{mmHg}$. 6units of packed cells and fresh frozen plasma, 3 units single donor platelets and cryoprecipitate were transfused, guided by Thromboelastography. Post reperfusion hemodynamics and blood gas status were stable. Surgery lasted for 10 hours, the patient was electively ventilated overnight and he was extubated the next day. 


\section{JMSCR Vol||05||Issue||11||Page 30824-30829||November}

\section{Postoperative course}

He was started on Cap. Tacrolimus 1mg twice daily. From day 1, we observed that the patient had poor verbal response, was lethargic with no appetite. Inj. Clexane 40U OD was started for thromboprophylaxis, from the $2^{\text {nd }}$ day. In the $3^{\text {rd }} 4^{\text {th }}$ and $5^{\text {th }}$ day the patient's muscle power was weak, had easy fatigability with tremors in the upper limb. Tacrolimus neurotoxicity was suspected, so it was switched over to cyclosporine 50mg twice daily. Tremors didn't subside, but worsened. The patient had dysarthria and quadriparesis by day 5.Patient's cognition and communication was deteriorating and gradually became drowsy by day 6. Workup for sepsis, liver functions, coagulation profile and electrolytes were normal. His thyroid profile showed normal TSH and low free T3 T4 enzymes. So the dose of Eltroxin was increased to $250 \mathrm{mics}$ expecting an improvement in his activity.

In day 6, at $3 \mathrm{am}$ the patient had sudden atrial fibrillation with a heart rate of 190/min and BP 90/60mgHg. Inj. Esmolol 100mic boluses were given twice with a loading dose of Inj. Amiodarone. It was observed that $\mathrm{AF}$ increased while CVP catheter manipulation and the cather was removed. The arrhythmia got reverted with in 10minutes. CT brain taken on day 8 was normal. He became comatose by day 8 , with a GCS of 3.The preoperative sodium was $132 \mathrm{mEq} / 1$ which rised to $140 \mathrm{mEq} / \mathrm{l}$ in the first 4 days. The rise was within the permissible limits of $8-10 \mathrm{mEq} / \mathrm{L}$.

There was steady increase in urea levels from 40 to $230 \mathrm{mg} \%$ over this period, with normal creatinine levels and urine output of $1 \mathrm{ml} / \mathrm{kg} / \mathrm{min}$. Suspecting azotemia as the cause of his neurological status , Slow Low Efficient Dialysis was done on $8^{\text {th }}$ day and urea reduced to $60 \mathrm{mg} \%$, but patient's mentation didn't improve and was mechanically ventilated.

MRI brain was done on the $11^{\text {th }}$ day. Expert opinion from the radiologist and neurologist, suggested features in favour of ODS. An acute embolic infarctin the frontal region and the residual hepatic enchephalopathic features that were seen in the preoperative period were also present.

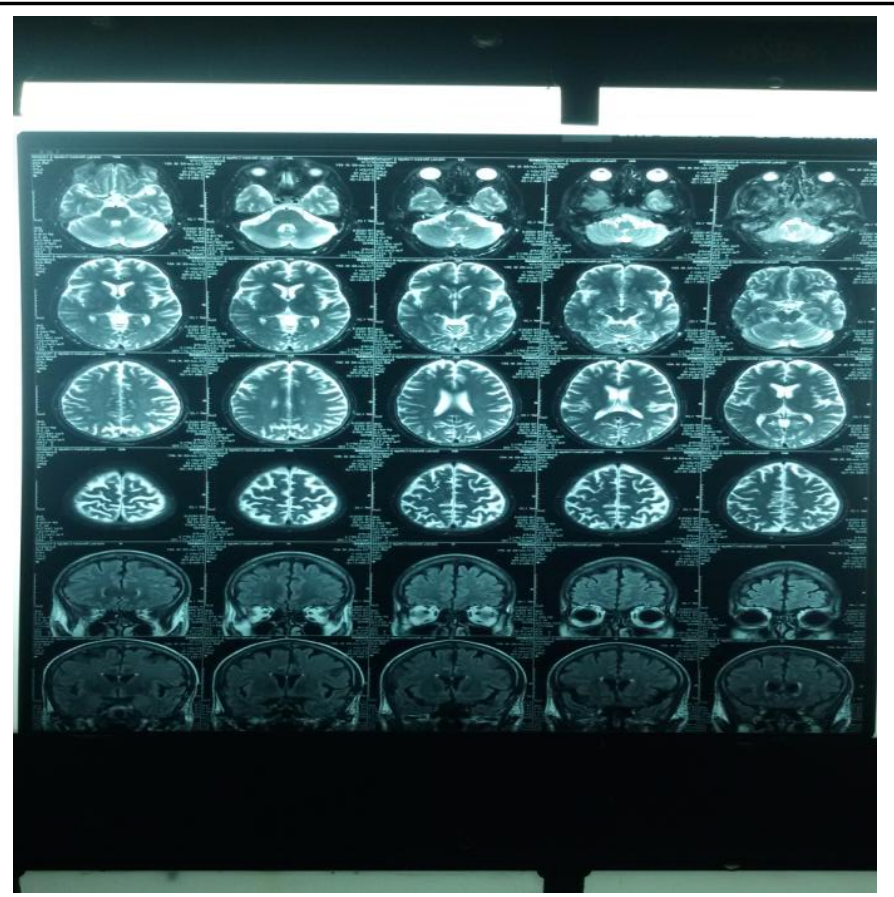

Fig 1a

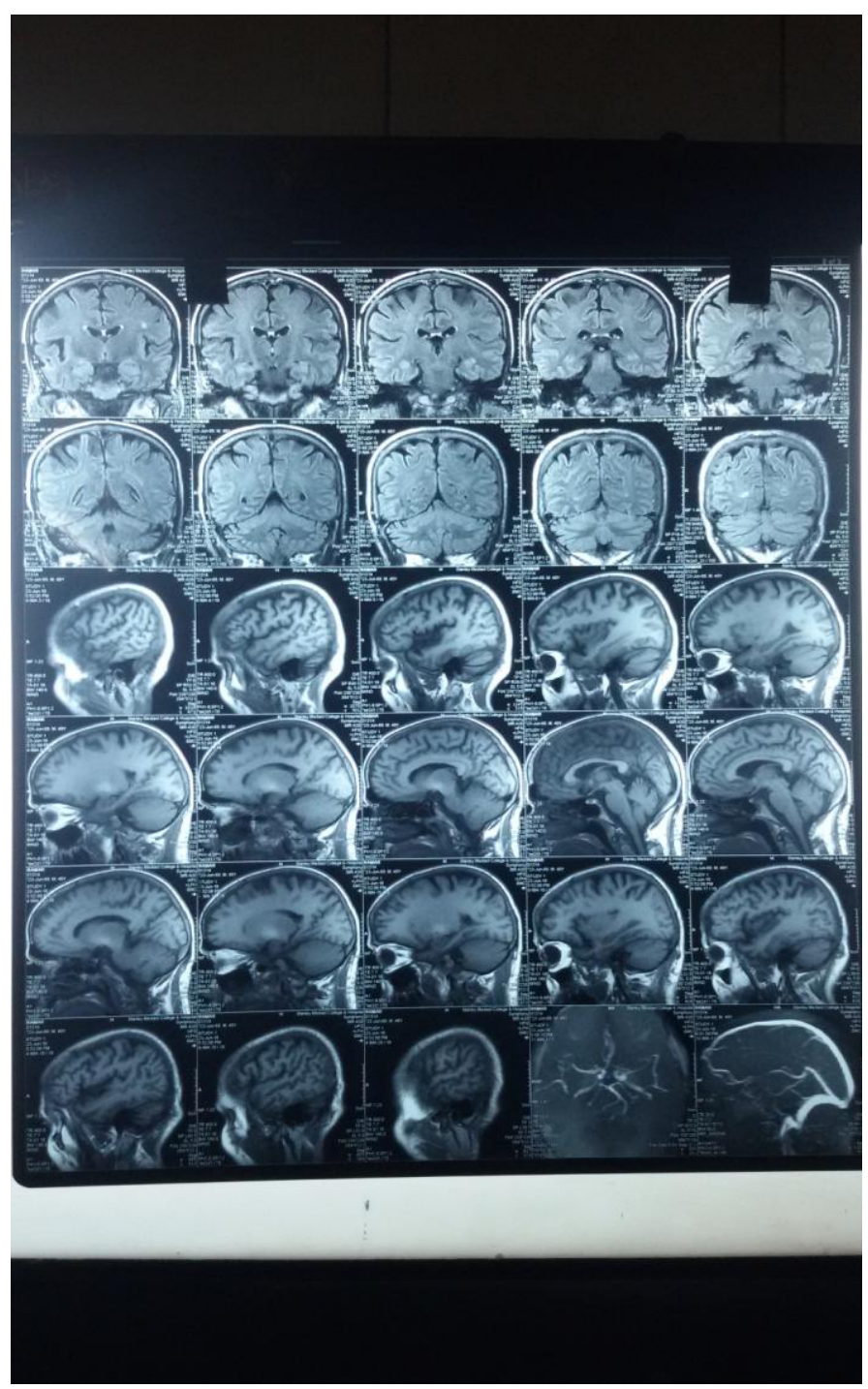

Fig $1 b$ 


\section{JMSCR Vol||05||Issue||11||Page 30824-30829||November}
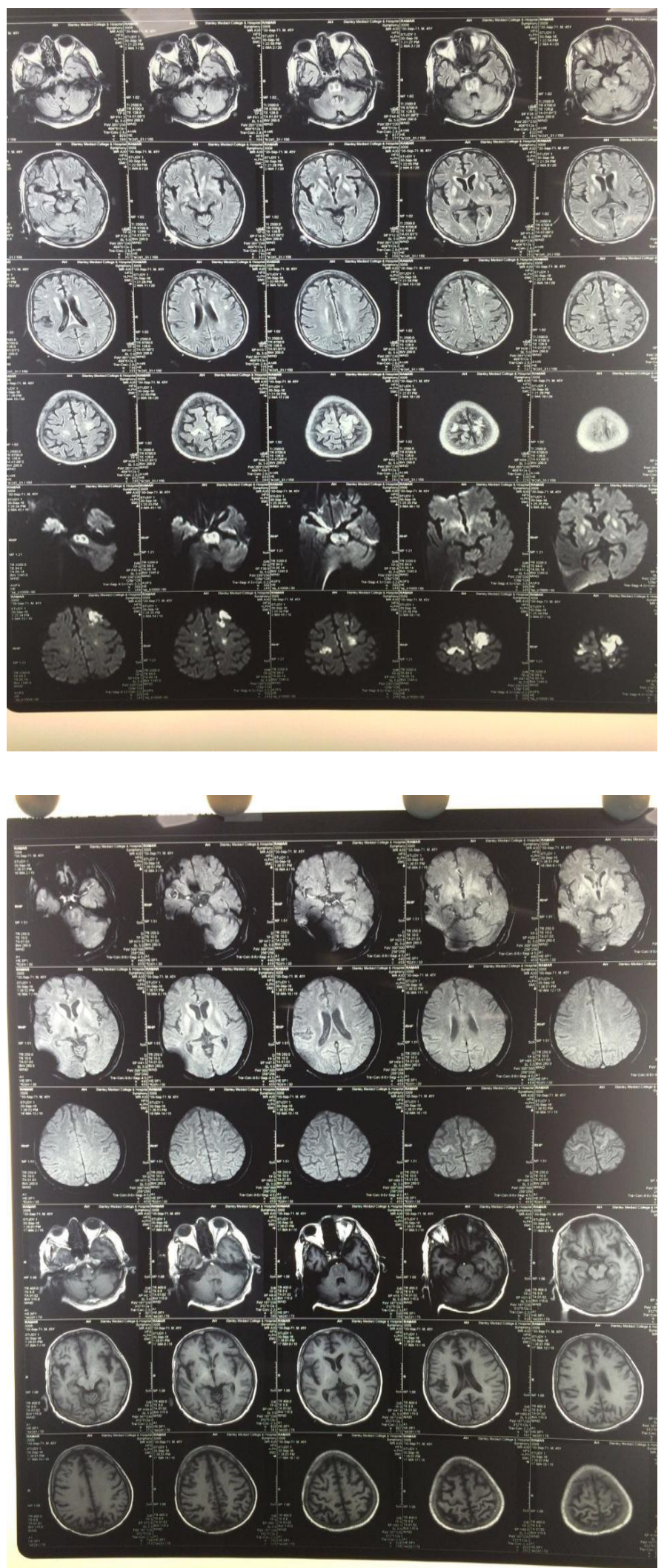

Fig 2a and Fig 2b - Features suggestive of acute embolic infarct involving left middle frontal gyrus, bilateral gyri, right frontal white matter (lacunar) and left precentral gyrus (lacunar). Hyperintensity in bilateral globus pallidus caudate nuclei hepatic encephalopathy/extrapontine myelinosis due to osmolyte imbalance. Hyperintensity in transverse pontine fibres- ?Vascular/extrapontine myelinosis due to osmolyte imbalance. Bilateral symmetrical hyperintensity of pyramidal tracts in precentral gyrus and in bilateral crus cerebri-? Hepatic encephalopathy)

We got a working diagnosis for his neurological status as ODS from his MRI. He was started on Tab. Aspirin $75 \mathrm{mg}$ once daily (OD), Tab. Clopilet $75 \mathrm{mg}$ OD, Tab. Atorvas 20mg HS, along with the neuroprotective drugs i.e Cap. Amantadine 100mg OD and Tab. Citicholine 500mg OD were added. Since the patient was unconscious, weaning from mechanical ventilation could not be done and percutaneous tracheostomy was performed. A Multimodal treatment approach was given in the next 50 days. Apart from the standard care and therapeutic regimen of a liver transplant patient, extra attention was given to nutrition, bed sore prevention and tracheostomy care. Upper and lower limb splints were applied to prevent contractures and prompt physiotherapy were given.

The patient gained consciouness by 60 days and slowly gained his motor power. All protective reflexes were normal and the tracheostomy was decannulated by 150th day. He was vocalising good, but had mild slurring of speech and was able to walk with support. Aggressive rehabilitative physiotherapy was continued.

In the $160^{\text {th }}$ day, patient had headache and his BP was $140 / 100 \mathrm{mmHg}$. Tab. Amlodipine 10mg BD was started for the hypertension and Tab. Paracetamol 500mg given for headache. MRI (Fig 2c) showed hemorrhage in the right lateral ventricle. Antithrombotic drugs were stopped and the BP settled to $120 / 70 \mathrm{mmHg}$ in the next two days. He was relieved of his headache, the hemorrhage did nt progress clinicaly, and it resolved without any new neurologic deficit. 


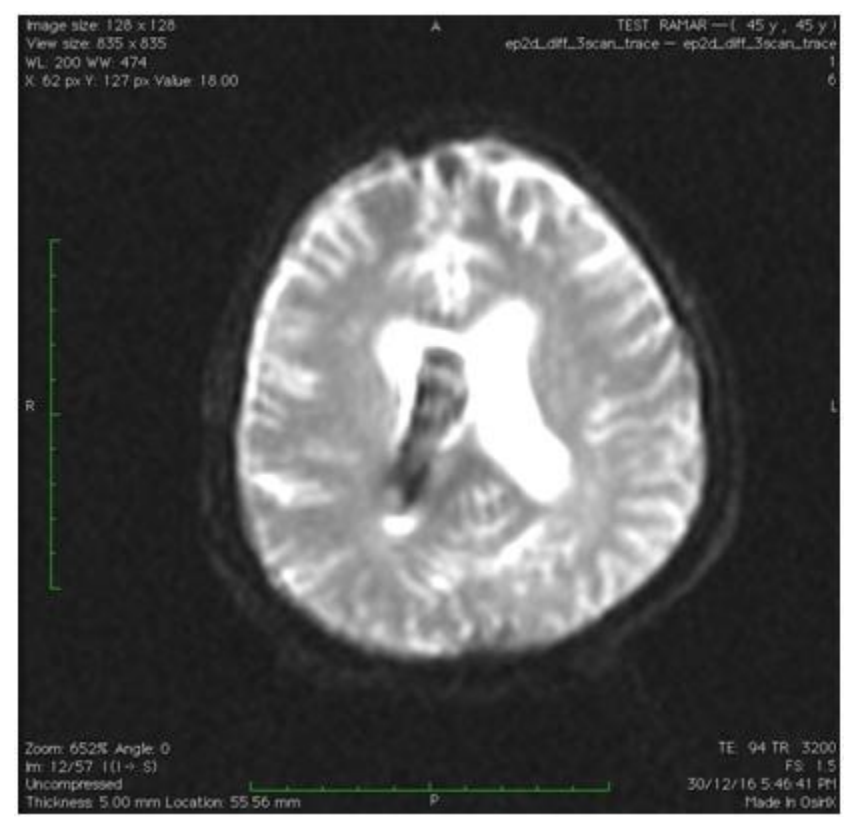

Fig 2c post surgical $160^{\text {th }}$ day developed hemorrhage in the right lateral ventricle

\section{Discussion}

Neurologic complications affects 15\%-30\% of liver transplant recipients ${ }^{[4]}$ and the risk factors ${ }^{[5,6,7,8]}$ are (i)Hepatic enchepalopathy due to alcohol abuse (ii)Perioperative hemodynamic instability ${ }^{[9]}$ (iii)Electrolyte and fluid shifts leading to ODS (iv) Immunosuppression related neurotoxicity (v) Cerebrovascular events(vi) opportunistic infections (vi)Malnutrition ${ }^{[10]}$ (vii)Sepsis and MODS.

This chronic alcoholic, malnourished patient had a BMI of $19.5^{[11]}$. The clinical features was bizarre in the $1^{\text {st }}$ days, with fatigue, behavioural change, dysarthria, muscle weakness and tremors. Initially Hepatic enchephalopathy due to graft dysfunction was suspected, but the Hepatic flow parameters and liver function tests were normal. Suspected neurotoxincity ${ }^{[28]}$ was ruled out, since no improvement after switching over to cyclosporine ${ }^{[29]}$ And the suspected azotemia(urea $230 \mathrm{mg} \%$ ) was also ruled out since the patient deteriorated even when urea came down (60mg\%), after SLED.

As per literature, even if there is subtle behavioural changes or muscle power weakness after transplant, possibility of ODS must be kept in mind ${ }^{[10][14]}$ Long duration of surgery is also a predisposing factor ${ }^{[13] \text {. }}$ ODS has two spectrums namely Cerbral Pontine Myelinolysis and Extra Pontine Myelinolysis.
Central pontine myelinolysis was described by Adams and colleagues in 1959 as a disease affecting alcoholics and the malnourished ${ }^{[11]}$. ODS has been reported in $1-8 \%$ of liver transplant recipients ${ }^{[6][7]}$ ${ }^{[12][14]}$. Hemodialysis has been quoted as a cause of ODS, but the patient had features of ODS even before dialysis was performed ${ }^{[15]}$.

\section{Pathogenesis of ODS}

The complex pathogenesis of ODS involves, the inability of brain cells to respond to rapid changes in osmolality of the extracellular compartment of the brain, leading to dehydration of energy-depleted cells with subsequent axonal damage that occurs in characteristic areas ${ }^{[16,17]}$. A decreased ability to generate new intracellular osmoles in response to osmotic change is present in DCLD ${ }^{[18,19]}$

In a retrospective study of 142 patients by Yun Ju et all in 2003 incidence of ODS is $3.5 \%$ after transplant. Liver failure is postulated to cause disruption of astrocyte metabolism with resulting abnormalities of blood brain barrier function.The results also suggested that operation time in patients with ODS was significantly longer, indicating prolonged low cerebral perfusion ${ }^{[13]}$.

\section{Clinical Features of ODS}

The clinical signs are dysarthria, dysphagia, movement disorders and quadriparesis. The patient presents with "locked-in syndrome"' with apparent change in consciousness. The patient can have psychiatric and beavioural changes. Whenever a gravely ill patient with alcoholism and malnutrition develops confusion, quadriplegia, pseudobulbar palsy and locked-in syndrome over a period of several days, ODS is the probable diagnosis. ${ }^{[20]}$

\section{Prevention and Treatment of ODS}

There is no specific treatment for non sodium dependent ODS rather than to treat the underlying illness and to initiate supportive measures ${ }^{[21]}$. Duration of the operation and intraoperative bleeding must be minimised. Major fluctuations in blood pressures and serum sodium during surgery must be avoided. 
Treatment with steroid, intravenous immunoglobulin, thyrotropin-releasing hormone, or plasma exchange has been reported in some cases. ${ }^{[22,23,24]}$

\section{Cerebrovascular Event}

Anoxic-ischemic events can occur early in the postoperative course ${ }^{[25][26]}$. Our patient has had an episode of transient arrhythmia with hypotension, in the $6^{\text {th }}$ POD. The stasis associated with clot formation could have been the source of emboli. CT done 2 days after that could not pick any infarct or any anoxic injury to the brain, but the MRI done 3 days after that picked up the acute embolic infarct. The hemorrage which occured in the $160^{\text {th }}$ day, can be attributed to the hypertension associated with cyclosporine, steroids and also the thrombotic propylaxis aspirin and LMWH. Martinez et al found that $24 \%$ of patients had evidence of cerebral hemorrhage, whereas $9 \%$ had evidence of infarcts, in an autopsy series ${ }^{\text {[27]. }}$

Guidelines to prevent cerebrovascular event as per the, European Federation of Neurological Societies, includes correction of coagulopathies, avoiding perioperative cerebral hypoperfusion, and control of cerebrovascular risk factors after liver transplantation, especially hypertension.

\section{Conclusion}

ODS is a common unforeseen complication, which can occur after liver transplant, especially in alcoholic malnourished patients. It can occur, even if, the change in sodium levels were within normal limits. A high index of suscpicion should be maintained under appropriate clinical settings, in patient like ours, who had multiple risk factors for developing neurological complications. Optimising nutritional status of the recipients preoperatively, avoiding major hemodynamic changes, minimising the duration of the surgery to prevent major fluid shifts are recommended to avoid osmotic stress to the brain, thereby ODS. Timely imaging, supportive measures and treatment of the associated complications will reduce mortality.

\section{References}

1. Rev. Bras. Anestesiol. vol.59 no.3 Campinas May/June 2009

2. Taneja K, Sabharwal RK, Taneja A et al. Central pontine myelinolysis in a normonatremic child. Indian Pediatr 1997;34:153-156.

3. Mast H, Gordon PH, Mohr JP et al - Central pontine myelinolysis: clinical syndrome with normal serum sodium. Eur J Med Res 1995; $1: 168-170$

4. Neurologic complications after liver transplantation. World J Hepatol 2013; 5(8): 409-416.

5. Bronster DJ, Emre S, Boccagni P, Sheiner PA, Schwartz ME, Miller CM. Central nervous system complications in liver transplant recipients--incidence, timing, and long-term follow-up. Clin Transplant. 2000; 14:1-7.

6. Lewis MB, Howdle PD. Neurologic complications of liver transplantation in adults. Neurology. 2003;61:1174-1178.

7. Saner F, Gu Y, Minouchehr S, Ilker K, Fruhauf NR, Paul A, Radtke A, Dammann M, Katsarava Z, Koeppen S, et al. Neurological complications after cadaveric and living donor liver transplantation. $\mathbf{J}$ Neurol. 2006;253:612-617.

8. Vizzini G, Asaro M, Miraglia R, Gruttadauria S, Filì D, D'Antoni A, Petridis I, Marrone G, Pagano D, Gridelli B. Changing picture of central nervous system complications in liver transplant recipients. Liver Transpl. 2011;17:1279-1285

9. Clinical Evolution of Central Pontine Myelinolysis in a Patient with Alcohol Withdrawal: A Blurred Clinical Horizon Abdul S. Mohammed, Prajwal Boddu, and Dina F. Yazdani

10. Wright DG, Laureno R, Victor M. Pontine and extrapontine myelinolysis. Brain1979; 102:361-85)

11. R. D. Adams, M. Victor, and E. L. Mancall, "Central pontine myelinolysis: a hitherto 
undescribed disease occurring in alcoholic and malnourished patients," Archives of Neurology and Psychiatry, vol. 81, no. 2, pp. 154-172, 1959.

12. Huq S, Wong $\mathrm{M}$, Chan $\mathrm{H}$ al - Osmotic demyelination syndromes: Central and extrapontine myelinosis. J Clinical Neuroscience 2007 ; 14:684 -688

13. Yu J Zheng, Liang TB, Shen Y, Wang WL, $\mathrm{Ke} \mathrm{QH}$. Possible causes of central pontine myelinolysis after liver ransplantation. World J Gastroenterol 2004; 10(17):2540 2543

14. Journal of Clinical Pathology 1991;44:909914 A P Boon, M P Carey, D H Adams, J Buckels, P McMaster)

15. Omotic demyelination syndrome in End stage Renal syndrome in End stage Renal Disease after recent hemodialysis: MRI of the brain. N. Cagla Tarhan, Muhtesem Agildere, U. Sibel Benli, F. Nurhan Ozdemir, Cuneyt Aytekin and Ufuk can. American journal of Roentgenology. Vol 182; Issue 3: pages 809-816, March 2004

16. AmJMed Sci. 2010 Jun;339(6):561-7. doi: 10.1097/MAJ.0b013e3181d3cd78.

17. Case reports in neurological medicine 2014.Osmotic Demyelination Syndrome as the Initial Manifestation of a Hyperosmolar Hyperglycemic State Article ID 652523,

18. Gankam Kengne F, Nicaise C, Soupart A, Boom A, Schiettecatte J, Pochet R, et al. Astrocytes are an early target in osmotic demyelination syndrome. J Am Soc Nephrol. 2011; 22: 1834-1845.

19. Burg MB, Ferraris JD. Intracellular organic osmolytes: function and regulation. J Biol Chem. 2008; 283: 7309-7313.

20. Wright DG, Laureno R, Victor M. Pontine and extrapontine myelinolysis. Brain1979; 102:361-85

21. osmotic Demyelination Syndrome Occurs Early in The Course of Hyperosmolar Hyperglycemic State. IOSR Journal of Dental and Medical Sciences (IOSR-
JDMS)2017.Volume 16, Issue 3 Ver. VII (March. 2017), PP 25-29

22. Extrapontine Myelinolysis treatment with TRH. Rev Neurol (paris)1998;154:163-165

23. Treatment of central pontine myelinolysis with therapeutic plasmapheresis Lancet $1999,353: 1155$

24. A case of central pontine myelinolysis with neurological recovery after administration of glucocorticoid. No to Shinkei 1991; 43:483488.

25. Pujol A, Graus F, Rimola A, et al: Predictive factors of inhospital CNS complications following liver transplantation. Neurology 1994;44:1226-1230.

26. Blanco R, De Girolami U, Jenkins RL, Khettry U: Neuropathology of liver transplantation. Clin Neuropathol 1995;14:109-117.

27. Martinez AJ, Estol C, Faris AA: Neurologic complications of liver transplantation. Neurol Clin 1988;6:327-348.

28. Small SL, Fukui MB, Bramblett GT, Eidelman BH. Immunosuppression-induced leukoencephalopathy from tacrolimus (FK506). Ann Neurol 1996; 40: 575-580 [PMID: $8871576 \quad$ DOI: 10.1002/ana.410400406]

29. Abouljoud MS , Kumar MS , Brayman KL, Emre S , Bynon JS ; OLN Study Group . Neoral rescue therapy in transplant patients with intolerance to tacrolimus. Clin Transplant $2002 ; 16: 168-72$. 